\title{
Imitation and culture: What gives?
}

\section{Cecilia Heyes (1)}

All Souls College \& Department of Experimental Psychology, University of Oxford, Oxford, UK

\section{Correspondence}

Cecilia Heyes, All Souls College \&

Department of Experimental Psychology, University of Oxford, High Street, Oxford OX1 4AL, UK.

Email: cecilia.heyes@all-souls.ox.ac.uk
What is the relationship between imitation and culture? This article charts how definitions of imitation have changed in the last century, distinguishes three senses of "culture" used by contemporary evolutionists (Culture ${ }^{1}$ Culture $^{3}$ ), and summarises current disagreement about the relationship between imitation and culture. The disagreement arises from ambiguities in the distinction between imitation and emulation, and confusion between two explanatory projects - the anthropocentric project and the cultural selection project. I argue that imitation gives cultural evolution an inheritance mechanism for communicative and gestural skills (but not technological skills), and cultural selection yields the cognitive mechanisms that make imitation possible.

\section{K E Y W O R D S}

anthropocentrism, cultural selection, culture, cumulative cultural evolution, emulation, imitation

\section{1 | INTRODUCTION}

Until recently, imitation was venerated as the key psychological ingredient of cumulative culture-successive improvement of socially learned behavioural adaptations over generations-and therefore essential to human success. Other animals were tested for imitation to find out whether they, like humans, are "smart" and "have culture." Now, increasingly, imitation is listed as just one of many contributors to cumulative culture or dismissed outright as over-rated. Why?

Recent experimental work with human and nonhuman animals does suggest that imitation, as now defined, is unlikely to play a prominent role in the cultural evolution of technology. 
However, there is a risk that this will lead us to overlook the importance of imitation in supporting group-specific postures, gestures, and ritual behaviours that are crucial for cooperation. I suggest that the imitation story encourages better integration between biological and cognitive sciences in the study of cultural evolution, and challenges us to ask whether complex cognitive processes, like imitation, are products as well as processes of cultural evolutionfruits as well as seeds of cumulative culture.

I begin the story with a brief outline of how and why definitions of imitation have changed over time. The third section distinguishes the three senses of "culture" used by contemporary evolutionists. The fourth section documents the range of contemporary views about the relationship between imitation and culture, while the fifth and sixth trace the roots of this disagreement to ambiguity in the distinction between imitation and emulation, and to confusion between two projects that motivate research on cultural evolution. In the final section, guided by the cultural selection project and data from cognitive science, I argue that the relationship between imitation and culture is bidirectional; imitation underwrites the cultural inheritance of gestural skills, and culture makes imitation possible.

\section{2 | IMITATION}

Since antiquity (Burrow, 2019), the term "imitation" has carried a "wide range of meaning, and is by some writers used in a broader, and by others in a narrower sense" (Morgan, 1900, p. 179). However, patchily and by degrees, a narrower sense has gained currency, first in cognitive science and later in research on cultural evolution (Heyes, 2021).

Writing at the turn of the 20th century, Gabriel Tarde (1895), a French sociologist, and James Mark Baldwin (1895), an American developmental psychologist, used "imitation" to refer to any influence of one mind on another; to any social influence on thought, emotion or behaviour. Even Edward Thorndike (1898), a comparative psychologist firm in distinguishing different types of learning, used "imitation" for all of the effects now called "social learning" (Galef, 1976).

Two prominent contemporaries, Charles Ellwood (1901) and Conwy Lloyd Morgan (1900), objected to Tarde's and Baldwin's liberal use of "imitation." However, rather than suggest that "imitation" be applied to a narrower range of social influences, they used qualifiers. For example, Morgan (1900) distinguished "instinctive imitation," "intelligent imitation" and "intentional imitation." If Morgan expected these terms to be used with care in subsequent research, like most definers and taxonomisers he would have been disappointed. Sixty years later, dismayed by the jumble of behaviours called "imitation" by ethologists, William H. Thorpe (1963, p. 135) defined "true imitation" as "the copying of a novel or otherwise improbable act or utterance, or some act for which there is clearly no instinctive tendency." The term "true imitation" caught on and continues to be used by some ethologists and comparative psychologists to this day (e.g., Zentall, 2006), but Thorpe's definition did not prove easy to apply. Is an "act" a body movement, an effect of that body movement on the environment, or both? Are there any acts for which there is "no instinctive tendency"?

Thirty years later, a widely cited article (Whiten \& Ham, 1992) worked both sides of the street, using imitation in the broad sense favoured by Morgan and Thorndike, and in the narrower sense pioneered by Thorpe as "true imitation." Whiten and Ham (1992) offered a taxonomy including four types of social influence on behaviour and four types of social learning. Their article was titled "On the nature and evolution of imitation in the animal kingdom," 
implying that "imitation" refers to all eight types (broad), but within the taxonomy imitation was defined as "B learns from A some part of the form of a behaviour" (narrow). Also, leaving questions about the nature of copying and of acts unresolved, Whiten and Ham (1992) did not explain what they meant by "form."

Outside research on animal behaviour, a more specific and less ambiguous definition of imitation began to gain currency in developmental psychology with the work of Piaget (1962) and took off when Meltzoff and Moore (1977) described as evidence of "neonatal imitation" reports that newborn human infants copy facial and manual gestures, such as tongue protrusion, mouth opening, and finger extension. In the 1990s, bringing the trend for narrower definition to research on animal behaviour, Tomasello, Kruger and Ratner (1993) distinguished "imitation" (learning by observation about "behavioural strategies") from "emulation" (learning by observation about the "affordances" of an object) and Heyes (1993) distinguished "imitative social learning" from "non-imitative social learning." Trying to clarify what is meant by "the form of a behaviour" (Whiten \& Ham, 1992), and "behavioural strategies" (Tomasello, Kruger \& Ratner, 1993), I defined imitation as learning by observation about behaviour, and (other) social learning as learning by observation about the environment. More specifically, in imitation an observer learns and reproduces something about the topography of body movementswhich part of the body to move (e.g., head or foot), or how to move body parts relative to one another (e.g., to bring appendages closer to the trunk or to move them further away)-whereas in other kinds of social learning, including stimulus enhancement and observational conditioning (Heyes, 1994), an observer learns about the location, characteristics or value of objects-for example, that there are nuts in a particular tree, that a stick bends, or that snakes are dangerous.

Since the 1990s, many scientists have retreated from the broad, everyday usage of "imitation"-from the legacy of Tarde, Baldwin, Morgan and Thorndike-and are now using "imitation" in the narrower sense, to refer to copying based on learning by observation about body movement topography. Those who have switched are primarily cognitive psychologists and neuroscientists who want to know whether there is any social learning that depends on distinctive neurocognitive mechanisms-mechanisms that are not involved in asocial learning, and that are either uniquely human or present only in a limited range of species. As we shall see, imitation narrowly defined is a good candidate for this role because it requires learners to solve a tricky correspondence problem. For behavioural ecologists and cultural evolutionists who are interested, not in minds or brains, but in the adaptive effects and population-level consequences of social learning, the broader sense of imitation remains serviceable. Problems arise only when the two senses are confused. For example, when evidence that one animal has attracted another's attention to food (imitation in the broad sense) is mistaken for evidence that the animal has copied body movement topography (imitation in the narrow sense).

Experiments using rigorous methods have produced reports of imitation in the narrow sense in "enculturated chimpanzees" (reared from birth by humans; Tomasello, Savage-Rumbaugh \& Kruger, 1993) and following "Do-as-I-do" training, in which animals are rewarded, on presentation of a distinctive cue, for producing actions that are progressively closer approximations to those of a model (Custance, Bard \& Whiten, 1995). All reports of imitation without explicit training in mother-reared chimpanzees and other nonhuman apes are controversial (Tennie, Call \& Tomasello, 2009; Whiten, 2017). Beyond primates, there is evidence of imitation in domesticated dogs (Fugazza \& Miklósi, 2014; Range, Huber \& Heyes, 2011) and in several bird species, including African Grey parrots, budgerigars, pigeons, and Japanese quail (Zentall, 2004). The parrots were socially bonded with their human trainers, and the dogs with 
their owners; like the chimpanzees that have tested positive for imitation, they were in some sense "enculturated."

Many of the studies involving birds and dogs have demonstrated "effector matching," use of the same body part as a model. For example, if the model uses her head to move an object, the observer is more likely to use his head than his hand or foot to produce the same outcome. This is regarded as imitation because the observer copies the way that one part of the body (e.g., the head) moves relative to the rest of the body (the trunk and appendages), but it is a minimal case. Copying the topography of body movement is distinct from copying the topography of object movement, sometimes called "emulation," but neither imitation nor emulation has a fixed or distinctive level of fidelity. When an impressionist copies the facial expressions of a celebrity, or a modern house dancer copies the fine details of a vogue, they are copying the topography of body movement with much greater precision than a human or nonhuman animal who imitates use of the head rather than the foot to move an object.

In many cases, imitation requires solution of a "correspondence problem" (Heyes \& Ray, 2000), conversion of the "seen but unfelt" movements of the model into the "felt but unseen" movements of the observer (Meltzoff \& Moore, 1997, p. 179). For facial expressions and whole-body movements, the visual feedback I receive when I perform an action is very different from what I see when I watch you performing the same action. Assuming I know my action looks like yours-that imitation would not be possible without knowledge of similarity-it has been suggested that imitation involves complex cognitive operations labelled "self-consciousness," "symbolic thought," or "intermodal matching" (Meltzoff \& Moore, 1983; Newen \& Vogeley, 2003). These terms have not been unpacked into a mechanistic or computational theory of imitation, but they have been influential. For example, they have encouraged researchers to distinguish firmly between "motor imitation" and "vocal imitation." Motor imitation is more commonly known simply as "imitation," copying the topography of body movements. Vocal imitation, which is said to occur when birds, cetaceans, and humans copy elements and sequences of speech and songs (but see Byrne \& Russon, 1998), is not thought to be a sign of cognitive complexity because it does not pose the correspondence problem. I hear similar things when I listen to your vocalisation and when I produce the same vocalisation myself. Therefore, I could copy a sound you make by simple trial-and-error, varying my vocal output until it matches my memory of the sounds you made. Likewise, emulation does not pose the correspondence problem because I could reproduce your effects on objects (e.g., moving food with a rake) by messing about until the look of my objects matches the look of yours. Crucially, these reflections-suggesting that motor imitation depends on greater cognitive complexity than vocal imitation or emulation-have made it plausible that motor imitation is a humanspecific or ape-specific adaptation for culture.

\section{3 | CULTURE}

In contemporary research on cultural evolution, three uses of "culture" are common, and they all link it with social learning-learning assisted by observation of, or interaction with, another agent or its products (Heyes, 1994; Hoppitt \& Laland, 2013). The term "culture" refers to: (a) information or behaviour acquired through social learning; (b) one or more socially learned behaviours shared by the members of a group; or (c) socially learned behaviours that are shared by members of a group and have improved over successive episodes of social learning (Heyes, 2020; Mesoudi \& Thornton, 2018; Whitehead, Laland, Rendell, Thorogood \& Whiten, 2019). 
The first definition (Culture ${ }^{1}$ ) suggests that culture is present in all species that are capable of social learning (Aplin, 2016). Snails have Culture ${ }^{1}$ because they sometimes find prey by following the slime trails of other snails (Webster \& Fiorito, 2001), and red-winged blackbirds have Culture $^{1}$ because they avoid foods consumed by other, sick blackbirds (Mason \& Reidinger, 1982). Culture ${ }^{1}$ is used to find out how social learning influences evolutionary dynamics across the animal kingdom (Laland, Kendal \& Kendal, 2009), and bears little resemblance to what most people, in science and elsewhere, regard as culture.

The second definition $\left(\right.$ Culture $^{2}$ ) is more restrictive. To count as Culture ${ }^{2}$, or a "tradition," a behaviour must be not only socially learned (sufficient for Culture ${ }^{1}$ ), but group-typical. It must be present in all or many members of one or a few social groups, and absent or rare in other social groups of the same species. And, crucially, the group-typicality must be due to the social learning, rather than to ecological or genetic differences between groups (see Koops, Visalberghi \& van Schaik, 2014 for a contrasting view). There is evidence of Culture ${ }^{2}$ in primates (Whiten, 2017) and other mammals (e.g., dolphins, meerkats, mongoose, whales; Whitehead, 2018), fish and birds (Aplin, 2019). In most species, there is evidence of Culture ${ }^{2}$ relating to just one behaviour-for example, mating site selection in coral reef fish, leaf-tool making in New Caledonian crows, or song dialect in passerine birds-but field studies (with limited potential to control for ecological variation) suggest that some groups of great apes have multiple traditions. For example, Schuppli and van Schaik (2019) have identified more than 20 behaviours - including "kiss-squeak" gestures, and creative uses of leaves - that vary across groups of orangutans in Borneo and Sumatra. Culture ${ }^{2}$ is more demanding than Culture ${ }^{1}$; animals that are capable of social learning (Culture $\left.{ }^{1}\right)$ might fail to show group-specific behaviour $\left(\right.$ Culture $^{2}$ ) because the effects of social learning quickly wash out of the learner's behaviour, or, as in the case of red-winged blackbirds, encourage dissimilarity rather than similarity between the behaviour of model (eat food X) and observer (avoid food X). The primary function of Culture ${ }^{2}$, as a scientific tool, is to identify behaviour in nonhuman animals that may illuminate the phylogenetic and ecological, social and cognitive factors that have produced the rich potential for group-typical behaviour, belief and technology found in our species.

Turning to Culture ${ }^{3}$ : The terms "cumulative culture" and "cumulative cultural evolution," used interchangeably, have become increasingly prominent since the 1990s (Boyd \& Richerson, 1996; Mesoudi \& Thornton, 2018; Tomasello, 1999). These terms suggest that social learning can not only make behaviour group-typical (Culture ${ }^{2}$ ), but improve behaviour over generations. You learn a certain knot from me, you discover an even better way of tying that knot, and the agents who learn from you inherit your improved method. Compelling critiques of the concept of cumulative cultural evolution are beginning to appear (Buskell, 2020; Stout, forthcoming).

Some cultural evolutionists believe that Culture $^{3}$ is uniquely human, while others argue that the regional variation in tool-use behaviour of chimpanzees and corvids provides evidence of cumulative culture. Notably, rigorous methods have revealed evidence of cumulative culture in pigeons. Sasaki and Biro (2017) found that pigeons can improve their homing skills by flying with a more experienced bird, and when they are put in transmission chains (i.e., after each novice has become an expert, it is paired with a new, naïve bird), homing performance improves over re-pairing generations.

The idea that culture can be equated with social learning (Culture ${ }^{1}$ ) is relatively new (e.g., Boyd \& Richerson, 1988), and socially learned group-typical behaviours (Culture ${ }^{2}$ ) used to be called "traditions" rather than culture (e.g., Galef, 1976). Consequently, it is possible that researchers are now using "cumulative culture" to protect Culture ${ }^{3}$ from a rising tide of other 
"cultures"; to avert the risk that "loose application of the term 'culture' for all socially learned behavior may obscure our ability to understand the evolution of what appear to be very unique characteristics of Homo sapiens" (Hill, 2009, p. 271).

\section{4 | CONTROVERSY}

When imitation is used in the broad sense-that is, equated with social learning-and culture is defined by social learning (Culture ${ }^{1}-$ Culture $^{3}$ ), it is necessarily true that imitation plays an essential role in culture. Under these circumstances, the statement "culture depends on imitation" is not a hunch or a scientific hypothesis, it is not something you can argue against or test in experiments, it is true by definition. Consequently, when Dawkins (1976) wrote that "memes," his atoms of culture, "propagate themselves in the meme pool by leaping from brain to brain via a process which, in the broad sense, can be called imitation" (p. 192), he was not setting up a target for empirical investigation, but telling us what he means by "meme." Similarly, and in another highly influential book on cultural evolution, when Boyd and Richerson (1988) characterised culture as "the transmission from one generation to the next, via teaching and imitation, of knowledge, values, and other factors that influence behavior" (p. 2), they were not raising the possibility that imitation plays a role in culture, but telling us what, for them, "culture" means.

When imitation is used in a narrower sense, as it has been increasingly since the 1990s, "Is imitation important for culture?" becomes an empirical question, and in recent years a wide range of answers have been offered. Tennie and his colleagues seem to have been most emphatic in answering "yes" (Tennie et al., 2009; Tennie, Hopper \& Van Schaik, forthcoming). They argue that imitation is necessary for the emergence of cumulative culture (Culture ${ }^{3}$ ); for the emergence of traits that have improved so much over generations that they cannot now be learned by trial-and-error alone, or even by asocial learning guided in a non-imitative way by the activities of other agents. (Tennie and colleagues often use "process copying," "action copying" or "form copying" rather than "imitation," but with reference to Tomasello et al.'s (1993) definition of imitation.) Defending this bold hypothesis - energetically and often with great ingenuity (e.g., Bandini, Motes-Rodrigo, Steele, Rutz \& Tennie, 2020) - Tennie and colleagues have argued that cumulative culture is uniquely human and of relatively recent origin. On this view, extant nonhuman apes have Culture ${ }^{1}$ and Culture $^{2}$ but not cumulative culture (Culture ${ }^{3}$; Reindl, Gwilliams, Dean, Kendal \& Tennie, 2020). Likewise, our hominin ancestors who used Oldowan and Acheulian stone tools showed group-specific behaviour that was due in some measure to social learning (Culture ${ }^{2}$ ), but, according to Tennie and colleagues, a "parsimonious" interpretation of the paleo-archaeological data suggests that these ancestors did not learn to make the tools by imitation, and therefore the tools were not products of cumulative culture (Tennie, Premo, Braun \& McPherron, 2017).

Other researchers continue to endorse the importance of imitation for cumulative culture but with less enthusiasm and exclusivity than Tennie and his colleagues. For example, in 2009 Tomasello reported that he saw imitation as less important for cumulative culture, and teaching and normativity as more important, than he had in 1993 (Tomasello et al., 1993; Tomasello, 2009). Similarly, prominent reviews have recently concluded that cumulative culture depends on "a package of sociocognitive capabilities (including teaching, imitation, verbal instruction and prosocial tendencies)" (Dean, Vale, Laland, Flynn \& Kendal, 2014, p. 299), and, similarly catholic, "a cluster of sociocognitive features" including imitation, emulation, mind reading (or theory of mind), language and egalitarian dispositions" (Whiten, 2017). 
This cooling towards imitation-loss of conviction that it plays an outstanding role in cumulative culture-is due in some measure to evidence that, in transmission chain experiments, human children (Reindl, Apperly, Beck, \& Tennie, 2017) and adults (Caldwell \& Millen, 2008, 2009; Caldwell, Schillinger, Evans \& Hopper, 2012) gain as much by observing the result of their predecessors' labour (emulation condition) as by observing the labour itself (imitation condition). For example, when each of a chain of groups constructs a tower using raw spaghetti, the height and/or strength of successive towers increases equally when members of group $n$ +1 observe the tower-making behaviour of group $n$ (imitation condition) and when group $n$ +1 is allowed only to view the tower made by group $n$ (emulation condition). Subsequent transmission chain experiments with adults have not only confirmed that improvement is no greater in the imitation than the emulation condition but suggested that neither imitation nor emulation is as effective as teaching (Morgan et al., 2015; Zwirner \& Thornton, 2015). (In these studies, and others inspired by behavioural ecology, individuals are said to have learned via "teaching" when they were offered active assistance by a knowledgeable individual. In contrast, "imitation" and "emulation" are used when the model does nothing intended to help the observer to learn. These semi-operational definitions obscure the fact that imitation and emulation may occur with or without teaching.)

The work of cognitive archaeologists has promoted yet deeper scepticism about the role of imitation in cumulative culture. Stout and colleagues (Stout \& Hecht, 2017; Stout \& Khreisheh, 2015) have found that contemporary humans require hundreds of hours of practice to develop basic skills in making Acheulian hand axes, the teardrop shaped tools that most researchers regard as the first clear evidence of cumulative culture in hominins. Even $167 \mathrm{hr}$ of training and practice, over 22 months, produced relatively little improvement in skill. Furthermore, when trying to identify the cognitive requirements for the development of knapping skill, Stout and Hecht (2017) found little value in "the dichotomy of high-fidelity process copying (imitation) vs. low-fidelity product copying (emulation) prevalent in discussions of cumulative culture" (p. 7863). Their analysis implies that any contribution of imitation to the cultural inheritance of Acheulian knapping is trivial compared with the perceptual and attentional abilities required to distinguish effective from ineffective strikes, and the temperamental capacities required to persist when learning is glacially slow.

Close to the sceptical extreme of the continuum we find field ethnographers reporting that contemporary groups of hunter-gatherers do not learn their skills by imitation or teaching (Hewlett, Fouts, Boyette \& Hewlett, 2011), or stressing instead the importance of norms in enabling cumulative culture (Hill, 2009; Perry, 2009). On the latter view, imitation may contribute to the transmission of technology but more "symbolic means" are required for the acquisition and enforcement of agreed standards of behaviour - the core features of human culture (Hill, 2009). But in answer to the question "Is imitation important for culture?," the most emphatic "no" has been given by cognitive anthropologists who study contemporary human symbolic traditions-for example, storytelling and flag designs. They assume that imitation is mediated by blind, "replicative" processes and argue that contemporary humans rarely, if ever, learn by imitation. Instead, in their view, human traditions are stabilised by "reconstructive" cognitive processes; by "communication, mindreading, and other forms of ordinary social interaction" (Acerbi, Charbonneau, Miton \& Scott-Phillips, 2019; Morin, 2016; discussed in Heyes, 2018a).

Why do contemporary researchers disagree so profoundly about the importance of imitation for culture? In the sections below I suggest that two problems are responsible and ways to resolve them. 


\section{5 | IMITATION AND EMULATION}

Since the 1990s, imitation has often been defined by contrast with emulation, but the imitationemulation distinction conflates two important dimensions of action. The "strategy" (Tomasello et al., 1993) or "form of behaviour" (Whiten \& Ham, 1992) involved in the performance of an instrumental task, such as using a rake to obtain food, involves two kinds of transformation: a sequence (linear or hierarchical; Byrne \& Russon, 1998) of changes in the spatial configuration of the actor's body parts (body movements), and of the objects on which she is acting (object movements). At its valuable core, the imitation-emulation distinction draws attention to what is copied by the observer: the body movements (imitation) or the object movements (emulation) or both. But this what distinction is typically mixed up with a how much distinction: between the copying of a sequence and the copying of an endpoint.

Consider the chimpanzee example that inspired Tomasello et al. (1993) to distinguish imitation from emulation (Tomasello, Davis-Dasilva, Camak \& Bard, 1987). In this study, juvenile chimpanzees who had observed an adult female, called "Lil One," using a T-bar to obtain outof-reach food were more successful in getting food with the T-bar than control subjects who had not seen Lil One demonstrating her skill. According to the typical way of distinguishing imitation and emulation, the greater success of the observers would be ascribed to imitation if they had copied Lil One's "strategies"; for example, if, like her, they "first used one hand to position the tool beyond the food and then reached through the fence with [their] other hand and dragged the tool (and the food) along the raised edge until it was within reach" (p. 177). In contrast, it would be classed as emulation if the experimental subjects merely reproduced the endpoint of Lil One's action-food and T of the T-bar close to the agent. Thus, in this example and elsewhere, the what and how much distinctions are confounded: Imitation differs from emulation because it (a) involves the reproduction of body (hand) movements as well as object (T-bar) movements, and (b) because it involves the reproduction of a sequence, not just a terminal configuration of body and objects.

If one focusses on how much, on the sequence dimension of the imitation-emulation distinction-casting imitation as "process copying" and emulation as "product copying" (Tennie et al., 2009) - it is almost inevitable that one will see imitation as a more powerful engine of cultural inheritance than emulation. This is because a focus on the sequence dimension makes it likely that imitation involves the transmission of more information than emulation. All other things being equal, learning a sequence by observation, $\mathrm{A}-\mathrm{B}-\mathrm{C}-\mathrm{D}$, requires acquisition of more information from the model than learning the endpoint, D only. Consequently, imitation (understood as sequence learning) is more likely than emulation (understood as endpoint learning) to result in faithful transmission, where fidelity is understood in terms of volume of information. If an observer encodes only the endpoint of a model's action (the terminal configuration of body and objects), and there is more than one sequence that can culminate in this endpoint, the sequence will be transmitted with lower fidelity. But we should not conclude from this that, in general, copying body movements is more important for culture than copying object movements. It tells us nothing about whether learning sequences of body movements by observation is more, less, or equally likely to promote cultural inheritance of skills compared with learning sequences of object movements by observation.

Confounding of what with how much in the imitation-emulation distinction may explain scepticism about Tennie's view that imitation is of fundamental importance for Culture ${ }^{3}$. Tennie and colleagues (e.g., 2020) can be interpreted as claiming that sequence learning by observation is crucial for culture, but they are often understood to be claiming, instead or in 
addition, that learning about body movements by observation is a necessary condition for culture. This would make sense for intransitive or object-free actions-the gestures, postures, and ritualistic body movements that promote within-group bonding and cooperation. Since these actions do not involve object movements, any social learning must be about body movements, and, alongside various forms of instruction, imitation is what enables agents to learn body movements from others. But it is clearly an open empirical question to what extent the cultural inheritance of instrumental actions-actions on objects-depends on copying body movements rather than object movements. Does the novice basket weaver learn more from watching the nimble movements of the expert's fingers, or from noting the way the weft is configured relative to the warp? Are there types of instrumental skill, or phases in instrumental skill acquisition, when observational learning about body movements dominates observational learning about object movements, or vice versa? I would be willing to bet that successful social learning about instrumental actions - the kind involved in making and using tools - is dominated by learning about object movements. However, in advance of dedicated experiments (e.g., using eye-tracking), it would be a brave person who claimed to know for sure whether imitation (understood as body movement copying) is more or less important than emulation (understood as object movement copying) for the cumulative cultural inheritance of instrumental skills (Heyes, 2013).

What can be done to prevent the imitation-emulation distinction from causing more confusion in future? In my view, it is not helpful to cast imitation and emulation as lying on a continuum, with "object movement reenactment" as a station halfway down the track (Whiten, Horner, Litchfield \& Marshall-Pescini, 2004; Whiten, McGuigan, Marshall-Pescini \& Hopper, 2009). This strategy obscures rather than illuminates differences in the cognitive demands and transmission potential of imitation and emulation. Rather, I suggest unpacking into four categories: Endpoint imitation-copying the endpoint of a sequence of body movements; sequence imitation-copying a sequence of body movements; endpoint emulationcopying the endpoint of a sequence of object movements; and sequence emulation-copying a sequence of object movements. Some cases of social learning fall squarely within just one of these four categories. Suppose an agent watches a model raising her outstretched arms in arcs to either side of her body and placing her hands on the top of her head. An observer who immediately put her hands on her head, but raised them via the shortest route, would be showing endpoint imitation, whereas an observer who, before placing her hands on her head, stretched out her arms and moved them through the same trajectories as the model would be showing sequence imitation. Similarly, imagine there was a re-run of the chimpanzee experiment described above (Tomasello et al., 1987; see Flynn \& Whiten, 2013 for an analogue in children) in which a screen allowed observers to see the effects of Lil One's body movements-the trajectories and interactions of the food and T-bar-but prevented them from seeing any part of Lil One's body. An observer who subsequently used the T-bar to rake the food but moved the T-bar through a different trajectory or brought the food into contact with a different part of the T-bar during the raking movement, would be showing endpoint emulation. In contrast, an observer who reproduced trajectories and interactions between the food and T-bar would be showing sequence emulation.

But any given case in the real world need not be pure. When agents observe a sequence of body movements and resulting object movements, as they did in the original experiment with Lil One, there is the opportunity for both kinds of imitation and both kinds of emulation. The observer might learn the sequence of body movements- using their left hand first, then both hands-and the sequence of object movements, moving the T-bar through the same trajectory 
as the model. Given the pervasiveness of "recency effects," better memory for terminal elements in a sequence than for earlier elements (Castro \& Larsen, 1992), we are unlikely to find sequence imitation without endpoint imitation, or sequence emulation without endpoint emulation. Similarly, given that attention is necessary for learning and that attention is a limited resource, we might expect an antagonistic relationship between imitation and emulation. For example, high attention to objects may be associated with low attention to bodies, and therefore there may be inverse relationships between endpoint emulation and endpoint imitation, and between sequence emulation and sequence imitation (Leighton, Bird \& Heyes, 2010). These hypotheses, based on the cognitive science of asocial learning and attention, need to be tested in a social context. If we want to know whether the members of a particular species are biased towards one of these four types of social learning, or about the task conditions that favour one of the four over the others, we need dedicated experiments to find out.

I am very deliberately describing endpoint imitation, sequence imitation, endpoint emulation, and sequence emulation as "types," "kinds," or "categories" rather than "mechanisms" of social learning. Like the undifferentiated categories, imitation and emulation, and indeed virtually every type of social learning given a name in the last century, they characterise what and how much is learned. For a radical behaviourist, this may be enough to make them "mechanisms" of learning, but for most psychologists since the 1960s learning mechanisms have been cognitive-software, running on the brain, that processes information from the world and generates behaviour. Clear delineation of what and how much is learned, by different species and in different task contexts, provides important clues about underlying cognitive mechanisms, but it is a basis for further enquiry, not an end-in-itself. To describe a cognitive mechanism is to characterise what goes on between an agent's ears, how the learner represents the information they receive from the outside world and the computations that transform it into behaviour. As we shall see below, some progress has been made in identifying the mechanisms of imitation, but emulation remains a black box (Stout \& Hecht, 2017; Tennie et al., forthcoming). For example, does it involve "causal understanding" and/or "template matching" (Jelbert, Hosking, Taylor \& Gray, 2018)? If so, what exactly is meant by "causal understanding" and "template matching"? How do the cognitive operations involved in causal understanding differ from those that track predictive relationships through associative learning? How does the template matching involved in emulation differ at the cognitive level from the processes that enable humans to draw and birds to build nests? Is information about serial order encoded via the same computations in sequence imitation and sequence emulation as it is when animals encode sequences of asocial events? None of these questions have been addressed.

Another caveat: I have broken down imitation and emulation into four categories because I think the aims of research on culture (see next section) will be served by getting clear about what and how much is learned by observation in the lab and in the field. But it is unlikely that any category of social learning can be reliably identified as high- or low-fidelity. We saw above that, all other things being equal, sequence learning is likely to involve transfer of more information than endpoint learning. However, it is not clear that, across tasks and species, all other things typically are equal, or that the term "fidelity" is used in research on cultural evolution only to refer to the amount of information transferred between agents. These topics deserve sustained analysis (Charbonneau \& Bourrat, 2021). Here, I want only to point out that even pure cases of endpoint imitation, sequence imitation, endpoint emulation, and sequence emulation will vary in their specificity. Compared with the model, the endpoint imitator might put her hands on exactly the same parts of her skull or only nearby: the sequence imitator may or may not splay her fingers in the same way as the model while she moves her arms upwards; the 
endpoint emulator might finish her movement with the food at the intersection between the two parts of T-bar or in contact with one end; and the sequence emulator might move the T-bar through roughly, rather than exactly, the same trajectory. Thus, each of these types of social learning comes in degrees; more or less information of a particular kind-about body movements or object movements, about sequences or endpoints-may be acquired by the observer from the model (Stout \& Hecht, 2017).

\section{6 | THE ANTHROPOCENTRIC AND CULTURAL SELECTION PROJECTS}

The second source of disagreement about the importance of imitation for culture relates to the purposes of research on cumulative culture. Two explanatory projects motivate research on Culture ${ }^{3}$ and they are often confused (Heyes, 2021). The anthropocentric project aims to explain human achievements and to identify forerunners of the relevant capacities in other animals. The cultural selection (or "third way," Heyes, 2018a) project asks whether Darwinian selection occurs among socially inherited traits (Campbell, 1974; Lewens, 2015), in humans or in other animals. It asks whether population behaviour can become better adapted through a process in which variants (skills, artefacts, beliefs, cognitive processes) are (a) generated by asocial learning and mistakes, rather than mutation, (b) inherited through social interaction rather than genetic mechanisms, and (c) where fitness depends on the holder's success in passing on their variant to unrelated individuals as well as biological offspring.

Two processes of population-level behavioural adaptation are already well-known: (a) The fit between a population's behaviour and the environment in which it occurs can be enhanced by genetic evolution. For example, natural selection acting on genetic variants is widely assumed to be the primary architect of dam-building behaviour in beavers. (b) At least in humans, the fit can also be improved by "intelligent design" (Dennett, 2009), through foresight and planning by individuals and groups. For example, anticipating the effects of heavy rainfall, a national government may coordinate the evacuation of people and construction of flood defences to mitigate the risk. The cultural selection project asks whether there is a third way in which the behaviour of a population can become adapted. The third way contrasts with genetic evolution in selecting among socially learned rather than genetically inherited variants. It contrasts with intelligent design because the adaptiveness of the selection does not depend on individuals or groups being smart enough to design novel solutions or to recognise what does and does not work (Clarke \& Heyes, 2017; Heyes, 2018b).

The anthropocentric and cultural selection projects can be difficult to tell apart. Many cultural evolutionists are interested in both projects. Some of these cultural evolutionists get their wires crossed, and others, in an entirely coherent way, see cultural selection as the answer to the anthropocentric question; as the thing that explains distinctively human achievements (Sterelny, 2012). But the difference between the anthropocentric and cultural selection projects, as they are usually pursued, is important. The anthropocentric project typically embraces the idea, advanced by "evolutionary psychology," that humans can do remarkable things because each of us is smart. In contrast, the cultural selection project pursues the possibility that many human achievements, and possibly those of other animals, depend on each agent being fairly dumb; that intelligence sometimes comes from the population-level process of cultural selection, rather than the workings of individual minds. 
Theories of "overimitation," which is thought to play a key role in Culture ${ }^{3}$, highlight the difference between the anthropocentric and cultural selection projects (Hoehl et al., 2019). Agents are said to overimitate when they copy causally irrelevant features of a model's behaviour. For example, in one of the original demonstrations of overimitation, 3-year and 4-year-old children who had watched an adult retrieve a toy from a box not only copied the actions necessary to get at the toy-lifting latches and opening doors-but also movements, such as tapping the box with a wand, that a typical Western adult would judge to be unnecessary to get the toy (Lyons, Young \& Keil, 2007). (Note that much of what is known as overimitation does not involve copying the topography of body movements; it is imitation in the old, broad sense.) Subsequent research has shown that overimitation occurs in a range of diverse cultures (Berl \& Hewlett, 2015; Nielsen, Mushin, Tomaselli \& Whiten, 2014), and in adolescents (Nielsen \& Tomaselli, 2010) and adults (McGuigan, Makinson \& Whiten, 2011) as well as children.

In principle, the thinking that produces overimitation could be foresighted or short-sighted. In the foresighted case, the observer might decide whether or not to copy an irrelevant action, such as wand tapping, following causal analysis of the apparatus (perhaps the vibration caused by the wand loosens the latch; Lyons et al., 2007); careful consideration of the model's intentions (maybe she tapped accidentally, or wanted to hear the noise, or expects me to tap regardless; Gardiner, Greif \& Bjorklund, 2011); and/or the normative context (could this be a ritual requiring me to act exactly the same way as other members of my group?; Keupp, Behne \& Rakoczy, 2013). In the short-sighted case, the observer might "decide" whether to copy only in a minimal sense. Having learned through past experience that there are circumstances where copying details of action has happy results-you get the toy, and others smile, nod and praise you-the observer has a default tendency to copy details in those circumstances. As long as she notices and remembers the model using the wand, and the context resembles those in which detail copying has had a happy outcome in the past, the observer just finds herself using the wand (Heyes, 2018b). She expects good consequences but beyond that she does not have a rationale.

For the anthropocentric project it does not matter much whether overimitation depends on foresighted or short-sighted cognitive processes. In either case, it provides the potential for high-fidelity social learning and thereby for cumulative culture. Foresighted processes are more likely to be ape-specific or human-specific, and therefore to support the idea that cumulative culture depends on complex pieces of cognitive kit produced by genetic evolution in the hominin line. But small, simple changes to short-sighted cognitive processes-increasing attention to other's actions and sensitivity to social rewards-could have made humans more likely to overimitate than other animals, and it would still be possible for the anthropocentric project to register these changes in other species as steps on the path to cumulative culture.

In contrast, for the cultural selection project the difference between foresighted and shortsighted processes is crucial. Insofar as the requirements for cumulative culture in a particular domain are met by foresighted cognitive processes, it suggests that improvement over generations is due to intelligent design (the second way; Amundson, 1989; Godfrey-Smith, 2012; Shea, 2009) rather than cultural selection (the third way). Agents who overimitate only when they have reasoned to the conclusion that it will pay-off in this particular case-for example, when the instrument is a wand, the box is opaque, the toy is still in the box, the model is familiar and present-are poised to be intelligent innovators, to change or drop the behaviour if, after all, it does not work for them. On the other hand, short-sighted overimitators, copying by default, are likely to be faithful carriers of the behaviour, keeping it in the population while cultural selection discovers a variant that is on average more effective across agents and environments. 
Confusion between the anthropocentric and cultural selection projects contributes in at least two ways to disagreement about the importance of imitation for culture. First, the anthropocentric project obscures the fact that cultural selection does not require taxonomically rare forms of social learning. Imitation, which is more highly developed in humans than in any other animals, may be important for the cultural inheritance of gestures and ritualistic body movements, but taxonomically widespread types of social learning, such as stimulus enhancement and observational conditioning (Heyes, 1994), are likely to be sufficient for the social transmission of many values (preferences and aversions), instrumental actions, and navigational skills (Heyes, 1993). Learning that chilli is good, or that handles open doors, does not require imitation, emulation or any other fancy type of social learning. There is evidence of Culture $^{3}$ in pigeons (Sasaki \& Biro, 2017) — not famous for their mental prowess—and in the dolphins of Shark Bay, Western Australia, where there are signs that a sponge-based foraging technique, learned in a cognitively undemanding way by juveniles from their mothers, is evolving via cultural selection (Smolker, Richards, Connor, Mann \& Berggren, 1997; Wild et al., 2019).

The fact that cultural selection does not require rare or complex types of social learning has been obscured, and ambivalence about imitation has been generated, because the anthropocentric project focusses attention on our close relatives, other great apes, and on the things that humans are especially good at. Humans are prodigious imitators and therefore the anthropocentric project promotes the assumption that imitation is important for culture. However, those who are interested in both cultural selection and the anthropocentric project realise (if only tacitly) that, depending on the trait, other forms of social learning can be just as effective as imitation in mediating cultural inheritance. Pulled in opposite directions by the two projects that interest them, and lacking a clear sense of how those projects differ, researchers compromise by listing imitation as one among many psychological ingredients of culture, with an unspecified role (Dean et al., 2014; Whiten, 2017).

Second, the archaeologists and anthropologists who are most sceptical about the importance of imitation are predominantly focussed on the anthropocentric project, and on how particular skills, norms and symbolic structures are sustained in human populations. When evidence emerges that those skills take years of practice to develop, as in the case of stone knapping (Stout \& Hecht, 2017; Stout \& Khreisheh, 2015), or when it is clear that the symbolic structures require language for their development (e.g., stories; Acerbi et al., 2019; Morin, 2016), many are understandably inclined to diminish the importance of imitation. For their purposes, imitation really is not important. In contrast, some of the biologists and psychologists who study social learning in animals are interested not only in the anthropocentric project but also in the cultural selection project. For them, imitation remains important, at least to some degree, because it is a plausible analogue of genetic replication in the cultural domain-and a potential means of acquiring the relatively simple, non-symbolic behaviours that they study.

\section{7 | FRUITS AND SEEDS}

If these two problems were resolved, what would we find? If what and how much were teased apart in imitation and emulation, and the anthropocentric and cultural selection projects were no longer confused, what would we discover about the relationship between imitation and culture? I think we would find that imitation is important for culture and that culture is important for imitation. 
I have already discussed what imitation gives to culture in Section 5 on "imitation versus emulation." There I argued that copying the topography of body movements (endpoints and/or sequences) is likely to contribute little to group-specificity (Culture ${ }^{2}$ ) and improvement (Culture $^{3}$ ) of instrumental skills-for example, tool-making and tool-using-but to be crucial for the cultural inheritance (Culture ${ }^{2}$ and Culture ${ }^{3}$ ) of gestural skills-object-free communicative and ritualistic body movements. Generalising the point: Task analysis suggests that imitation, narrowly defined, is not a good candidate for the cultural inheritance of technology, and that it is indispensable for the cultural inheritance of gestures. The difference between successful and unsuccessful tools lies in the topography of objects, not of body movements. When a stone knapper is producing a hand axe, whether the next strike detaches a flake, making the blade sharper, or destroys the whole project by shattering the core, depends on the location, force and direction with which the hammer stone hits the core-not on the body movements used to wield the hammer. The right interaction between the hammer and core is easier to achieve with some body movements than others-for example, when the hammer is gripped with the whole hand-but this would swiftly become apparent to the novice through their own experience. In contrast, the difference between successful and unsuccessful gestures depends crucially on how parts of the body move relative to one another. If I lower rather than raise my eyebrows, I am expressing doubt rather than surprise; the "ok" sign is meaningless unless the tips of the forefinger and thumb come together; shaking the upper body is "shimmying" only if the shoulders move back and forward in alternation. Consequently, imitation is likely to play a major role in the cultural inheritance of communicative and ritualistic behaviours-behaviours that are known to have a powerful effect on cooperation within groups (Watson-Jones \& Legare, 2016).

Now, let us turn to the inverse relationship, the role of culture in building the cognitive capacity for imitation. The cultural selection project raises the possibility that a range of complex cognitive processes are fruits rather than seeds of culture. In the past, under the influence of the anthropocentric project, it has been widely assumed that Culture ${ }^{2}$ and Culture ${ }^{3}$ require social learning based on complex foresighted cognitive processes-not only the capacity to copy the topography of body movements (imitation), but also the ability to understand models' intentions ("mindreading," "theory of mind," or "shared intentionality"), and to weigh up the pros and cons of copying one model rather than another ("social learning strategies"). In other words, it was assumed that complex cognitive processes are the seeds of culture; once they have evolved in a lineage, via genetic inheritance, there is the potential for significant regional variation in behaviour (Culture ${ }^{2}$ ) and for improvement of socially learned traits over generations $\left(\right.$ Culture $^{3}$ ). The cultural selection project makes clear that this need not be the case. Cultural selection could produce Culture ${ }^{2}$ and Culture ${ }^{3}$ without complex cognition. Adaptation via cultural selection, like adaptation via genetic selection, requires offspring to be similar to their parents, and a tendency for more effective variants to be copied more often than less effective variants, but it does not require these conditions to be met via complex forms of social learning (Birch \& Heyes, 2021).

If imitation and other complex cognitive processes are not the seeds of culture, is it just a coincidence that humans are both smart and awash with culture? Do our capacities for imitation, theory of mind and other complex cognitive processes have nothing to do with our outstanding diversity (Culture ${ }^{2}$ ) and propensity to improve socially learned behaviour over generations $\left(\right.$ Culture $\left.^{3}\right)$ ? That seems very unlikely, but an alternative solution to the puzzle is emerging: Recent research on the childhood development of imitation, theory of mind, and other complex cognitive processes suggests that-like beliefs, preferences, technologies and 
social conventions - these cognitive processes are products of culture; fruits rather than seeds of cultural selection (Heyes, 2018b, 2020; Heyes, Chater \& Dwyer, 2020).

The evidence that culture produces imitation comes from studies testing the associative sequence learning (ASL, or "cognitive gadget") theory of imitation (Catmur, Walsh \& Heyes, 2009; Cook, Bird, Catmur, Press \& Heyes, 2014; Heyes \& Ray, 2000). This theory offers a mechanistic account of how the "seen but unfelt" is converted into the "felt but unseen" (Meltzoff \& Moore, 1997); how the correspondence problem is solved for imitation. It suggests that humans are prodigious imitators, not because we have complex, genetically inherited cognitive processes on the inside, but because we have complex social resources on the outside. According to the ASL theory, imitators do not need to know that their action is similar from a third-party perspective to the action of the model. Instead of computing the similarity between seen and felt actions, agents learn binary associations between observed and executed actions (Figure 1). Whenever an agent gets temporally correlated experience of seeing and doing the same action (e.g., sees a shoulder moving forward when moving her own shoulder forward), basic mechanisms of learning connect a sensory representation with a motor representation of that action; the two representations enter a "matching vertical association" (sometimes encoded in mirror neurons, Cook et al., 2014; Heyes \& Catmur, 2021). Once a vertical association is in place, sight of the action activates the motor representation enabling imitation of the action. But vertical associations do not only enable imitation of familiar actions (sometimes called "mimicry" or "response facilitation"). Once there is a large set of vertical associations, they act as a vocabulary enabling imitation of new actions (sometimes called "imitation learning"): When a new action sequence is observed, motor representations are activated in the order the action components are perceived. For example, in the case of shimmying, the observer sees: left shoulder forward, left shoulder back, right shoulder forward, right shoulder back. Successive activation of these motor representations allows the observer to learn the new movement sequence as if she were practicing by moving her own body. On the inside, learning matching vertical associations requires only the basic mechanisms of associative learning that produce Pavlovian conditioning in a broad range of vertebrate and invertebrate species. On the outside, it requires a complex social environment to provide a rich supply of correlated sensorimotor experience. For example, correlated experience of seeing-and-doing is provided by optical mirrors, action words, ritual practices involving synchronous action, and childrearing practices that encourage adults to imitate infants and children.

The ASL theory has been tested over the last 20 years in experiments with adults, children and nonhuman animals, using behavioural and neural measures (Catmur et al., 2009; Cook et al., 2014). It is consistent with the evidence that nonhuman apes and dogs can be trained to imitate using the do-as-I-do procedure, and that animals raised by humans-apes, dogs, and parrots-are superior imitators. According to the ASL theory, training works by establishing matching vertical associations, and the active ingredient of "enculturation" of nonhuman animals is exposure to the artefacts and social practices that foster imitation in human children. The theory is also supported by evidence that human children imitate vocalisations, hand gestures, and actions that make a noise (e.g., banging a hand on a table), before they imitate facial expressions and whole-body movements. Self-observation (e.g., listening to your own actions, or watching your own hand in motion) is sufficient to form vertical associations for the former but not the latter (Ray \& Heyes, 2011). Most striking, the gadget theory has been tested and confirmed by experiments showing that the propensity to imitate, and the properties of mirror neurons, can be transformed by novel sensorimotor experience. For example, passive observation of index finger movement normally activates index finger muscles in the observer's hand. 


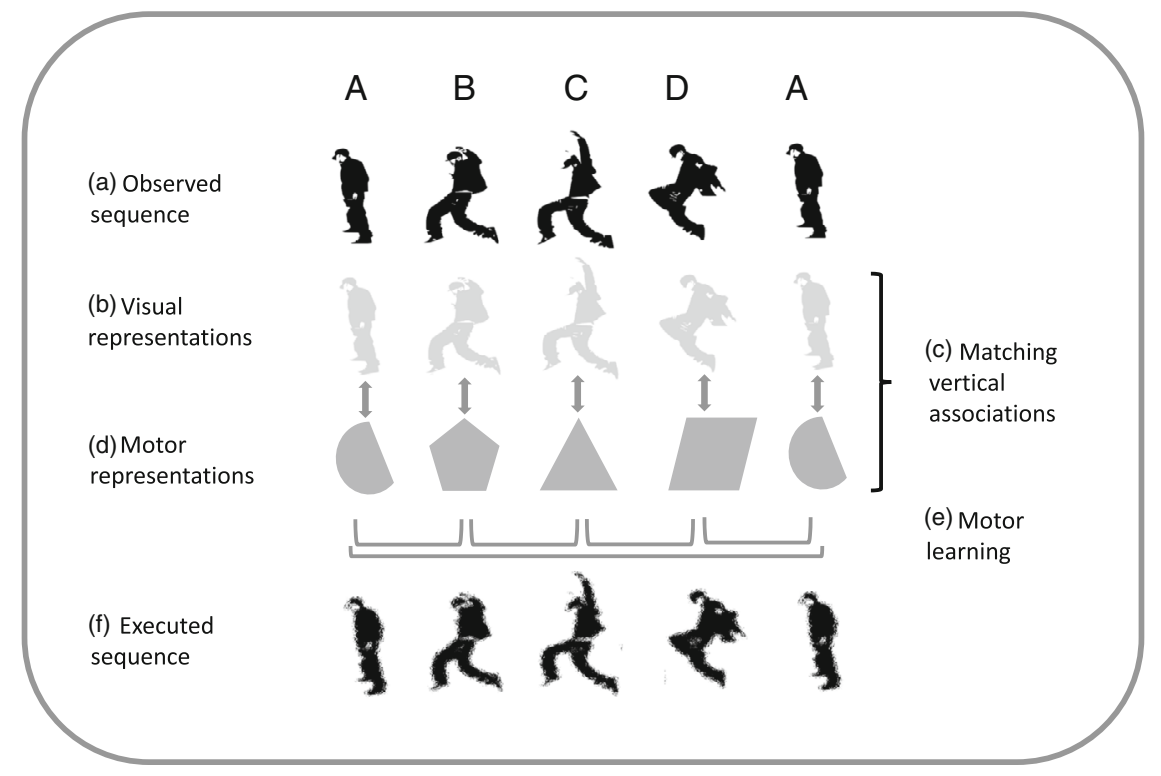

F I G U RE 1 The associative sequence learning (or "cognitive gadget") model of imitation. (a) The agent observes a novel action sequence. He has performed each component before but not as part of this sequence. (b) Observation of each component activates a visual representation in the agent's cognitive system. Successive activation of the visual representations, A-B-C-D-A, results in perceptual sequence learning. By itself, perceptual sequence learning would enable the agent to recognise the sequence in future but not to reproduce it. (c) Prior to observing the novel action sequence, the agent had learned a matching vertical association for each action component. For example, as is common in dance training, he may have looked in a mirror while performing a component, or performed a component repeated while observing others doing the same to a musical beat. (d) Through the action of the vertical association, each visual representation activates a motor representation. The visual and motor parts of a matching vertical association have similar content, for example, they both represent component $\mathrm{C}$, but this content is coded in different ways, illustrated here using pictorial (visual) and geometric (motor) shapes. (e) Successive activation of the motor representations enables the cognitive system to learn the action sequence as if the agent was practicing, that is, performing the sequence himself. (f) Successive activation of the motor representations also makes it possible, but not obligatory, for the agent to reproduce the observed action sequence, that is, to imitate. Fidelity varies with attention to the observed sequence, individual differences in motor coordination, whether the observer has a vertical association for all components, and the precision of the match between visual and motor representations in each vertical association. For example, precision will be low if $\mathrm{B}$ and $\mathrm{C}$ were not distinct visual and/or motor representation prior to observing the new sequence

However, after training in which people respond to index finger movements with little finger movements, and vice versa, observation of index finger movement produces more activity in little finger than in index finger muscles (Catmur, Mars, Rushworth \& Heyes, 2011; Catmur, Walsh \& Heyes, 2007). Imitation is converted by sensorimotor learning into counter-imitation.

Although consistent with research involving adults, children and nonhuman animals, the ASL theory of imitation is at odds with reports that newborn monkeys and newborn humans can copy a range of facial and manual gestures. If newborns can do it, the capacity to imitate is a seed rather than a fruit; genetically rather than culturally inherited. However, neonatal imitation has been controversial since it was first reported in humans in the 1970s (Meltzoff \& Moore, 1977), and recent work by a group in Brisbane, led by Virginia Slaughter, provides 
compelling evidence that it is not a reliable phenomenon (Slaughter, 2021). I will summarise this work in some detail because it is new and important. As far as I am aware, putative evidence of neonatal imitation is the only evidence that imitation is a genetically inherited "seed" for culture.

First, monkeys: A set of 10 studies from one research group have claimed to provide evidence of imitation in newborn monkeys (e.g., Ferrari et al., 2006; Wooddell, Simpson, Murphy, Dettmer \& Paukner, 2019). These studies did not use the two-action or cross-target procedure which has been agreed, by both enthusiasts and sceptics, to be necessary to detect imitation in newborns (e.g., Meltzoff \& Moore, 1977; Ray \& Heyes, 2011). For example, when testing for imitation of tongue-protrusion and lip-smacking, they did not use these behaviours as controls for one another. Instead of looking for a higher frequency of tongue protrusion than of lipsmacking in infants who had just observed tongue protrusion, and a higher frequency of lipsmacking than of tongue protrusion in infants who had just observed lip-smacking, they reported, for example, a higher frequency of tongue protrusion after observation of tongue protrusion than after observation of a rotating disk. An effect of this kind could be due, not to imitation of tongue protrusion, but to a biological, social stimulus eliciting more behaviour of all kinds than a nonbiological, asocial stimulus. Pointing out this problem alongside several others (e.g., multiple statistical comparisons without correction), a member of the Brisbane group reanalysed the data from the full corpus of 10 neonatal monkey studies. Applying the cross-target methodology, the re-analysis found no evidence whatever of imitation in newborn monkeys (Redshaw, 2019).

The Brisbane group's work with human neonates points in the same direction. In a study with unprecedented power, Oostenbroek et al. (2016) tested more than 100 infants longitudinally at 1, 3, 6 and 9 weeks of age, in a cross-target procedure involving a wide range of targets. They recorded the frequencies of nine target actions-tongue protrusion, mouth opening, happy expressions, sad expressions, index finger protrusion, grasping, MMM sound, EEE sound, tongue click-while infants observed 11 movement stimuli-an adult performing each of the nine actions, and two object movements. The results of the study were wholly negative: In no case did the infants consistently perform a target action more often while observing the same action than while observing the alternative actions. Re-analysing the data from this study, using a more liberal statistical method, Meltzoff et al. (2018; see also Oostenbroek et al., 2018) found evidence of imitation for one of the nine target actions - tongue protrusion. Although consistent with other reviews and meta-analyses of neonatal imitation data (e.g., Anisfeld et al., 2001; Jones, 2006; Ray \& Heyes, 2011), this result does not uphold the historical claim that newborns are capable of voluntary imitation of a range of actions (Meltzoff \& Moore, 1977).

Previous failures to find neonatal imitation have been attributed to methodological factors-for example, to the use of an inappropriate model, an inadequate response interval, or sub-optimal statistical procedures. A recent meta-analysis of neonatal imitation research by the Brisbane group, encompassing 336 effect sizes dating back to 1977, sought and did not find a modulating influence of 13 methodological factors previously cited as reasons for replication failure (Davis et al., 2021). However, the meta-analysis did find a modulating effect of "researcher affiliation"; a small number of laboratories are more likely than others to find large positive effects. Furthermore, across the whole data set there was a relationship between standard error and effect size indicative of publication bias; that is, suggesting that smaller studies have been conducted, found no evidence of neonatal imitation, and not been published.

In combination with the data from adults, children and nonhuman animals supporting the ASL model, the Brisbane studies suggest that newborns do not imitate and, in line with the 
ASL model, that the capacity for imitation is constructed through correlated sensorimotor experience. Since most of this experience comes from interaction with other agents and with artefacts such as mirrors, this implies that Culture ${ }^{2}$, group-specific ritual and childrearing practices, are crucially important for the development of imitation, and that imitation may be a product of Culture ${ }^{3}$, successive improvement via cultural group selection (Heyes, 2018b).

\section{8 | CONCLUSION}

Imitation has shrunk and culture has expanded. When imitation was equated with social learning, and culture with socially learned behaviour, the importance of imitation for culture was guaranteed by definition. Now that imitation is understood as copying the topography of body movements, and the focus is on cumulative culture (Culture ${ }^{3}$ ), the relationship between imitation and culture is contentious. Different researchers suggest that imitation is crucial, one of many ingredients, or involved in Culture ${ }^{2}$ and Culture ${ }^{3}$ only in a trivial way. I have argued that much of this disagreement is due to conceptual tangles between imitation and emulation, and between the anthropocentric and cultural selection projects. When these tangles are combed out, the evidence from adults, children and nonhuman animals suggests that imitation gives culture an inheritance mechanism for communicative and ritualistic actions (but not technological skills). In return, culturally inherited rituals, artefacts and childrearing practices give humans the capacity to imitate.

\section{ACKNOWLEDGEMENTS}

Thanks to several sharp and kind colleagues who commented on components of this paper while it was in preparation: Tim Lewens, Kim Sterelny, Dietrich Stout, and Alex Thornton. This article is a sequel to a piece I published nearly 30 years ago in Animal Behaviour on "Imitation, culture and cognition." I continue to be grateful to the people who got me interested in these topics-Henry Plotkin and Bennett Galef.

\section{DATA AVAILABILITY STATEMENT}

There are no data relevant to this manuscript.

\section{ORCID}

Cecilia Heyes (iD https://orcid.org/0000-0001-9119-9913

\section{REFERENCES}

Acerbi, A., Charbonneau, M., Miton, H. \& Scott-Phillips, T. (2019). Cultural stability without copying. Worldwide Universities Network. https://doi.org/10.31219/osf.io/vjcq3

Amundson, R. (1989). The trials and tribulations of selectionist explanations. In K. Hahlweg \& C. A. Hooker (Eds.), Issues in evolutionary epistemology (pp. 413-432). Albany, NY: State University of New York Press.

Anisfeld, M., Turkewitz, G., Rose, S. A., Rosenberg, F. R., Sheiber, F. J., Couturier-Fagan, D. A. \& Sommer, I. (2001). No compelling evidence that newborns imitate oral gestures. Infancy, 2, 111-122.

Aplin, L. (2016). Understanding the multiple factors governing social learning and the diffusion of innovations. Current Opinion in Behavioral Sciences, 12, 59-65.

Aplin, L. M. (2019). Culture and cultural evolution in birds: A review of the evidence. Animal Behaviour, 147, 179-187.

Baldwin, J. M. (1895). Mental development in the child and the race. New York, NY: Macmillan. 
Bandini, E., Motes-Rodrigo, A., Steele, M. P., Rutz, C. \& Tennie, C. (2020). Examining the mechanisms underlying the acquisition of animal tool behaviour. Biology Letters, 16, 20200122.

Berl, R. E. \& Hewlett, B. S. (2015). Cultural variation in the use of overimitation by the Aka and Ngandu of The Congo Basin. Public Library of Science One, 10, e0120180.

Birch, J. \& Heyes, C. (2021). The cultural evolution of cultural evolution. Philosophical Transactions of the Royal Society B, 376, 20200051.

Boyd, R. \& Richerson, P. J. (1988). Culture and the evolutionary process. Chicago, IL: University of Chicago Press.

Boyd, R. \& Richerson, P. J. (1996). Why culture is common, but cultural evolution is rare. Proceedings of the British Academy, 88, 77-93.

Burrow, C. (2019). Imitating authors: Plato to futurity. Oxford: Oxford University Press.

Buskell, A. (2020). Cumulative culture and complex cultural traditions. Mind \& Language, 1-20. https://doi.org/ 10.1111/mila.12335

Byrne, R. W. \& Russon, A. E. (1998). Learning by imitation: A hierarchical approach. Behavioral and Brain Sciences, 21, 667-684.

Caldwell, C. A. \& Millen, A. E. (2008). Experimental models for testing hypotheses about cumulative cultural evolution. Evolution and Human Behavior, 29, 165-171.

Caldwell, C. A. \& Millen, A. E. (2009). Social learning mechanisms and cumulative cultural evolution: Is imitation necessary? Psychological Science, 20, 1478-1483.

Caldwell, C. A., Schillinger, K., Evans, C. L. \& Hopper, L. M. (2012). End state copying by humans (Homo sapiens): Implications for a comparative perspective on cumulative culture. Journal of Comparative Psychology, 126, 161-169.

Campbell, D. T. (1974). Evolutionary epistemology. In P. A. Schilpp (Ed.), The philosophy of Karl Popper (pp. 412-463). La Salle, IL: Open Court.

Castro, C. A. \& Larsen, T. (1992). Primacy and recency effects in nonhuman primates. Journal of Experimental Psychology: Animal Behavior Processes, 18, 335.

Catmur, C., Mars, R. B., Rushworth, M. F. \& Heyes, C. (2011). Making mirrors: Premotor cortex stimulation enhances mirror and counter-mirror motor facilitation. Journal of Cognitive Neuroscience, 23, 2352-2362.

Catmur, C., Walsh, V. \& Heyes, C. (2007). Sensorimotor learning configures the human mirror system. Current Biology, 17, 1527-1531.

Catmur, C., Walsh, V. \& Heyes, C. (2009). Associative sequence learning: The role of experience in the development of imitation and the mirror system. Philosophical Transactions of the Royal Society B, 364, 2369-2380.

Charbonneau, M. \& Bourrat, P. (2021). Fidelity and the grain problem in cultural evolution. Synthese, 1-22.

Clarke, E. \& Heyes, C. (2017). The swashbuckling anthropologist: Henrich on the secret of our success. Biology and Philosophy, 32, 289-305.

Cook, R., Bird, G., Catmur, C., Press, C. \& Heyes, C. (2014). Mirror neurons: From origin to function. Behavioral and Brain Sciences, 37, 177-192.

Custance, D. M., Bard, K. A. \& Whiten, A. (1995). Can young chimpanzees (Pan troglodytes) imitate arbitrary actions? Hayes and Hayes (1952) revisited. Behaviour, 132, 837-859.

Davis, J., Redshaw, J., Suddendorf, T., Nielsen, M., Kennedy-Costantini, S., Oostenbroek, J. \& Slaughter, V. (2021). Does neonatal imitation exist? Insights from a meta-analysis of 336 effect sizes. Perspectives on Psychological Science, 1-25. https://doi.org/10.1177/1745691620959834

Dawkins, R. (1976). The selfish gene. Oxford: Oxford University Press.

Dean, L. G., Vale, G. L., Laland, K. N., Flynn, E. \& Kendal, R. L. (2014). Human cumulative culture: A comparative perspective. Biological Reviews, 89, 284-301.

Dennett, D. (2009). Darwin's "strange inversion of reasoning”. Proceedings of the National Academy of Sciences, 106(S1), 10061-10065.

Ellwood, C. A. (1901). The theory of imitation in social psychology. American Journal of Sociology, 6, 721-741.

Ferrari, P. F., Visalberghi, E., Paukner, A., Fogassi, L., Ruggiero, A. \& Suomi, S. J. (2006). Neonatal imitation in rhesus macaques. Public Library of Science, Biology, 4, e302.

Flynn, E. \& Whiten, A. (2013). Dissecting children's observational learning of complex actions through selective video displays. Journal of Experimental Child Psychology, 116, 247-263.

Fugazza, C. \& Miklósi, Á. (2014). Deferred imitation and declarative memory in domestic dogs. Animal Cognition, 17, 237-247. 
Galef, B. G. (1976). Social transmission of acquired behavior: A discussion of tradition and social learning in vertebrates. Advances in the Study of Behavior, 6, 77-100.

Gardiner, A. K., Greif, M. L. \& Bjorklund, D. F. (2011). Guided by intention: Preschoolers' imitation reflects inferences of causation. Journal of Cognition and Development, 12, 355-373.

Godfrey-Smith, P. (2012). Darwinism and cultural change. Philosophical Transactions of the Royal Society B, 367, 2160-2170.

Hewlett, B. S., Fouts, H. N., Boyette, A. H. \& Hewlett, B. L. (2011). Social learning among Congo Basin huntergatherers. Philosophical Transactions of the Royal Society B, 366, 1168-1178.

Heyes, C. (2013) What can imitation do for cooperation? In K. Stereiny, R. Joyce, B. Calcott, \& B Fraser (Eds.) Cooperation and Its Evolution. MIT Press.

Heyes, C. (2018a). Enquire within: Cultural evolution and cognitive science. Philosophical Transactions of the Royal Society B, 373, 20170051.

Heyes, C. (2018b). Cognitive gadgets: The cultural evolution of thinking. Boston, MA: Harvard University Press.

Heyes, C. (2020). Culture: A primer. Current Biology, 30, PR1246-PR1250.

Heyes, C. (2021). Imitation: A primer. Current Biology, 31, R228-R232.

Heyes, C. \& Catmur, C. (2021). What happened to mirror neurons? Perspectives on Psychological Science. https:// doi.org/10.1177/1745691621990638

Heyes, C., Chater, N. \& Dwyer, D. M. (2020). Sinking in: The peripheral Baldwinisation of human cognition. Trends in Cognitive Sciences, 24, 884-899.

Heyes, C. (1993). Imitation, culture and cognition. Animal Behaviour, 46, 999-1010.

Heyes, C. (1994). Social learning in animals: Categories and mechanisms. Biological Reviews, 69, $207-231$.

Heyes, C. \& Ray, E. D. (2000). What is the significance of imitation in animals? Advances in the Study of Behavior, 29, 215-245.

Hill, K. (2009). Animal “culture”? In K. N. Laland \& B. G. Galef (Eds.), The question of animal culture (pp. 269-287). Cambridge, MA: Harvard University Press.

Hoehl, S., Keupp, S., Schleihauf, H., McGuigan, N., Buttelmann, D. \& Whiten, A. (2019). “Over-imitation”: A review and appraisal of a decade of research. Developmental Review, 51, 90-108.

Hoppitt, W. \& Laland, K. N. (2013). Social learning: An introduction to mechanisms, methods, and models. Princeton, NJ: Princeton University Press.

Jelbert, S. A., Hosking, R. J., Taylor, A. H. \& Gray, R. D. (2018). Mental template matching is a potential cultural transmission mechanism for New Caledonian crow tool manufacturing traditions. Scientific Reports, 8, 1-8.

Jones, S. S. (2006). Exploration or imitation? The effect of music on 4-week-old infants' tongue protrusions. Infant Behavior and Development, 29, 126-130.

Keupp, S., Behne, T. \& Rakoczy, H. (2013). Why do children overimitate? Normativity is crucial. Journal of Experimental Child Psychology, 116, 392-406.

Koops, K., Visalberghi, E. \& van Schaik, C. P. (2014). The ecology of primate material culture. Biology Letters, 10(11), 20140508.

Laland, K. N., Kendal, J. R. \& Kendal, R. L. (2009). Animal culture: Problems and solutions. In K. N. Laland \& B. G. Galef (Eds.), The question of animal culture (pp. 174-197). Cambridge, MA: Harvard University Press.

Leighton, J., Bird, G. \& Heyes, C. (2010). "Goals” are not an integral component of imitation. Cognition, 114, 423-435.

Lewens, T. (2015). Cultural evolution: Conceptual challenges. Oxford: Oxford University Press.

Lyons, D. E., Young, A. G. \& Keil, F. C. (2007). The hidden structure of overimitation. Proceedings of the National Academy of Sciences, 104, 19751-19756.

Mason, J. R. \& Reidinger, R. F. (1982). Observational learning of food aversions in red-winged blackbirds (Agelaius phoeniceus). The Auk, 99, 548-554.

McGuigan, N., Makinson, J. \& Whiten, A. (2011). From over-imitation to super-copying: Adults imitate causally irrelevant aspects of tool use with higher fidelity than young children. British Journal of Psychology, 102, 1-18.

Meltzoff, A. N. \& Moore, M. K. (1977). Imitation of facial and manual gestures by human neonates. Science, 198, 75-78.

Meltzoff, A. N. \& Moore, M. K. (1983). Newborn infants imitate adult facial gestures. Child Development, 54, 702-709. 
Meltzoff, A. N. \& Moore, M. K. (1997). Explaining facial imitation: A theoretical model. Infant and Child Development, 6, 179-192.

Meltzoff, A. N., Murray, L., Simpson, E., Heimann, M., Nagy, E., Nadel, J. \& Subiaul, F. (2018). Re-examination of Oostenbroek et al. (2016): Evidence for neonatal imitation of tongue protrusion. Developmental Science, 21 , e12609.

Mesoudi, A. \& Thornton, A. (2018). What is cumulative cultural evolution? Proceedings of the Royal Society B, $285,20180712$.

Morgan, C. L. (1900). Animal behaviour. London: E. Arnold Press.

Morgan, T. J., Uomini, N. T., Rendell, L. E., Chouinard-Thuly, L., Street, S. E., Lewis, H. M., ... Laland, K. N. (2015). Experimental evidence for the co-evolution of hominin tool-making teaching and language. Nature Communications, 6, 1-8.

Morin, O. (2016). How traditions live and die. Oxford: Oxford University Press.

Newen, A. \& Vogeley, K. (2003). Self-representation: Searching for a neural signature of self-consciousness. Consciousness and Cognition, 12, 529-543.

Nielsen, M., Mushin, I., Tomaselli, K. \& Whiten, A. (2014). Where culture takes hold: "Overimitation" and its flexible deployment in Western, Aboriginal, and Bushmen children. Child Development, 85, $2169-2184$.

Nielsen, M. \& Tomaselli, K. (2010). Overimitation in Kalahari Bushman children and the origins of human cultural cognition. Psychological Science, 21, 729-736.

Oostenbroek, J., Redshaw, J., Davis, J., Kennedy-Costantini, S., Nielsen, M., Slaughter, V. \& Suddendorf, T. (2018). Re-evaluating the neonatal imitation hypothesis. Developmental Science, 22, e12720.

Oostenbroek, J., Suddendorf, T., Nielsen, M., Redshaw, J., Kennedy-Costantini, S., Davis, J., ... Slaughter, V. (2016). Comprehensive longitudinal study challenges the existence of neonatal imitation in humans. Current Biology, 26, 1334-1338.

Perry, S. (2009). Are nonhuman primates likely to exhibit cultural capacities like those of humans? In K. N. Laland \& B. G. Galef (Eds.), The question of animal culture (pp. 247-268). Cambridge, MA: Harvard University Press.

Piaget, J. (1962). Play, dreams and imitation in childhood (C. Gattegno \& F. H. Hodgson, Trans.). New York, NY: WW Norton.

Range, F., Huber, L. \& Heyes, C. (2011). Automatic imitation in dogs. Proceedings of the Royal Society B, 278, 211-217.

Ray, E. \& Heyes, C. (2011). Imitation in infancy: The wealth of the stimulus. Developmental Science, 14, 92-105.

Redshaw, J. (2019). Re-analysis of data reveals no evidence for neonatal imitation in rhesus macaques. Biology Letters, 15, 20190342.

Reindl, E., Apperly, I. A., Beck, S. R., \& Tennie, C. (2017). Young children copy cumulative technological design in the absence of action information. Scientific Reports, 7(1), 1-11.

Reindl, E., Gwilliams, A. L., Dean, L. G., Kendal, R. L. \& Tennie, C. (2020). Skills and motivations underlying children's cumulative cultural learning: Case not closed. Palgrave Communications, 6, 1-9.

Sasaki, T. \& Biro, D. (2017). Cumulative culture can emerge from collective intelligence in animal groups. Nature Communications, 8, 1-6.

Schuppli, C. \& van Schaik, C. P. (2019). Animal cultures: How we've only seen the tip of the iceberg. Evolutionary Human Sciences, 1, E2. https://doi.org/10.1017/ehs.2019.1

Shea, N. (2009). Imitation as an inheritance system. Philosophical Transactions of the Royal Society B, 364, 2429-2443.

Slaughter, V. (2021). Do newborns have the ability to imitate? Trends in Cognitive Sciences, 25, $377-387$.

Smolker, R., Richards, A., Connor, R., Mann, J. \& Berggren, P. (1997). Sponge carrying by dolphins (Delphinidae, Tursiops sp.): A foraging specialization involving tool use? Ethology, 103, 454-465.

Sterelny, K. (2012). The evolved apprentice. Boston, MA: MIT Press.

Stout, D. (forthcoming). What is "cumulative" evolution? Current Anthropology.

Stout, D. \& Hecht, E. E. (2017). Evolutionary neuroscience of cumulative culture. Proceedings of the National Academy of Sciences, 114, 7861-7868.

Stout, D. \& Khreisheh, N. (2015). Skill learning and human brain evolution: An experimental approach. Cambridge Archaeological Journal, 25, 867-875.

Tarde, G. (1895). La logique sociale. Paris: Félix Alcan. 
Tennie, C., Call, J. \& Tomasello, M. (2009). Ratcheting up the ratchet: On the evolution of cumulative culture. Philosophical Transactions of the Royal Society B, 364, 2405-2415.

Tennie, C., Hopper, L. \& Van Schaik, C. P. (2020). 19 On the Origin of Cumulative Culture: Consideration of the Role of Copying in Culture-Dependent Traits and a Reappraisal of the Zone of Latent Solutions Hypothesis. In L. M. Hopper and S. R. Ross (Eds.), Chimpanzees in Context (pp. 428-453). University of Chicago Press.

Tennie, C., Premo, L. S., Braun, D. R. \& McPherron, S. P. (2017). Resetting the null hypothesis: Early stone tools and cultural transmission. Current Anthropology, 58, 652-672.

Thorndike, E. L. (1898). Animal intelligence: An experimental study of the associative processes in animals. The Psychological Review: Monograph Supplements, 2(4), i.

Thorpe, W. H. (1963). Learning and instinct in animals. London: Methuen and Co.

Tomasello, M. (1999). The cultural origins of human cognition. Cambridge, MA: Harvard University Press.

Tomasello, M. (2009). The question of animal culture, plus postscript (chimpanzee culture, 2009). In K. N. Laland \& B. G. Galef (Eds.), The question of animal culture. Boston, MA: Harvard University Press.

Tomasello, M., Davis-Dasilva, M., Camak, L. \& Bard, K. (1987). Observational learning of tool-use by young chimpanzees. Human Evolution, 2, 175-183.

Tomasello, M., Kruger, A. C. \& Ratner, H. H. (1993). Cultural learning. Behavioral and Brain Sciences, 16, 495-511.

Tomasello, M., Savage-Rumbaugh, S. \& Kruger, A. C. (1993). Imitative learning of actions on objects by children, chimpanzees, and enculturated chimpanzees. Child Development, 64, 1688-1705.

Watson-Jones, R. E. \& Legare, C. H. (2016). The social functions of group rituals. Current Directions in Psychological Science, 25, 42-46.

Webster, S. J. \& Fiorito, G. (2001). Socially guided behaviour in non-insect invertebrates. Animal Cognition, 4, 69-79.

Whitehead, H. (2018). Culture and social learning. In Encyclopedia of marine mammals (pp. 232-234). Academic Press.

Whitehead, H., Laland, K. N., Rendell, L., Thorogood, R. \& Whiten, A. (2019). The reach of gene-culture coevolution in animals. Nature Communications, 10, 1-10.

Whiten, A. (2017). Social learning and culture in child and chimpanzee. Annual Review of Psychology, 68, $129-154$.

Whiten, A. \& Ham, R. (1992). On the nature and evolution of imitation in the animal kingdom: Reappraisal of a century of research. Advances in the Study of Behavior, 21, 239-278.

Whiten, A., Horner, V., Litchfield, C. A. \& Marshall-Pescini, S. (2004). How do apes ape? Animal Learning \& Behavior, 32, 36-52.

Whiten, A., McGuigan, N., Marshall-Pescini, S. \& Hopper, L. M. (2009). Emulation, imitation, over-imitation and the scope of culture for child and chimpanzee. Philosophical Transactions of the Royal Society B: Biological Sciences, 364, 2417-2428.

Wild, S., Krützen, M., Rankin, R. W., Hoppitt, W. J., Gerber, L. \& Allen, S. J. (2019). Long-term decline in survival and reproduction of dolphins following a marine heatwave. Current Biology, 29, R239-R240.

Wooddell, L. J., Simpson, E. A., Murphy, A. M., Dettmer, A. M. \& Paukner, A. (2019). Interindividual differences in neonatal sociality and emotionality predict juvenile social status in rhesus monkeys. Developmental Science, 22, e12749.

Zentall, T. R. (2004). Action imitation in birds. Animal Learning \& Behavior, 32, 15-23.

Zentall, T. R. (2006). Imitation: Definitions, evidence, and mechanisms. Animal Cognition, 9, 335-353.

Zwirner, E. \& Thornton, A. (2015). Cognitive requirements of cumulative culture: Teaching is useful but not essential. Scientific Reports, 5, 1-8.

How to cite this article: Heyes, C. (2023). Imitation and culture: What gives? Mind \& Language, 38(1), 42-63. https://doi.org/10.1111/mila.12388 